\title{
Increased atypical PKC expression and activity in the phrenic motor nucleus following cervical spinal injury
}

\author{
C.H. Guenther ${ }^{1,3}$, J.A. Windelborn ${ }^{1,4}$, T.C. Tubon Jr. ${ }^{2,5}$, J.C.P. Yin ${ }^{2}$, and G.S. Mitchell ${ }^{1}$ \\ ${ }^{1}$ Department of Comparative Biosciences, University of Wisconsin, Madison, WI USA, 53706 \\ ${ }^{2}$ Department of Genetics, University of Wisconsin, Madison, WI USA, 53706
}

\section{Abstract}

\begin{abstract}
Atypical protein kinase $\mathrm{C}(\mathrm{aPKC})$ isoforms are expressed in phrenic motor neurons, a group of motor neurons critical for breathing. Following $\mathrm{C}_{2}$ cervical hemisection $\left(\mathrm{C}_{2} \mathrm{HS}\right)$, spontaneous plasticity occurs in crossed-spinal synaptic pathways to phrenic motor neurons, at least partially restoring inspiratory phrenic activity below the injury. Since aPKCs are necessary for synaptic plasticity in other systems, we tested the hypothesis that $\mathrm{C}_{2} \mathrm{HS}$ increases aPKC expression and activity in spinal regions associated with the phrenic motor nucleus. $\mathrm{C}_{2}$ laminectomy (sham) or $\mathrm{C}_{2} \mathrm{HS}$ was performed on adult, male Lewis rats. Ventral spinal segments $\mathrm{C}_{3-5}$ were harvested 1, 3 or 28 days post-surgery, and prepared for aPKC enzyme activity assays and immunoblots. Ventral cervical aPKC activity was elevated 1 and 28 , but not 3 , days post- $\mathrm{C}_{2} \mathrm{HS}$ ( 1 day: 63\% vs sham ipsilateral to injury; $\mathrm{p}<0.05 ; 28$ day: $426 \%$ vs sham; $\mathrm{p}<0.05$; no difference in ipsilateral vs contralateral response). Total $\mathrm{PKC} \zeta / \imath$ protein expression was unchanged by $\mathrm{C}_{2} \mathrm{HS}$, but total and phosphorylated PKM $\zeta$ (constitutively active PKC $\zeta$ isoform) increased ipsilateral to injury 28 days post- $\mathrm{C}_{2} \mathrm{HS}(\mathrm{p}<0.05)$. Ipsilateral aPKC activity and expression were strongly correlated $\left(\mathrm{r}^{2}=0.675\right.$, $\mathrm{p}<0.001)$. In a distinct group of rats, immunohistochemistry confirmed that aPKCs are expressed in neurons 28 days post-C2HS, including large, presumptive phrenic motor neurons; aPKCs were not detected in adjacent microglia (OX-42 positive cells) or astrocytes (GFAP positive cells). Changes in aPKC expression in the phrenic motor nucleus following $\mathrm{C}_{2} \mathrm{HS}$ suggests that aPKCs may contribute to functional recovery following cervical spinal injury.
\end{abstract}

\section{INTRODUCTION}

Respiratory failure is a major cause of death in the first year following spinal injury in humans, and respiratory complications are the leading cause of death after the first year (Winslow and Rozovsky, 2003). Thus, mechanisms of spontaneous or induced plasticity in spinal pathways to respiratory motor neurons are of considerable interest as a means of preserving and/or restoring respiratory function (Mitchell, 2007; Vinit et al., 2009; DaleNagle et al., 2010).

\footnotetext{
(C) 2012 Elsevier Inc. All rights reserved.
}

Corresponding Address: G.S. Mitchell, Department of Comparative Biosciences, School of Veterinary Medicine, University of Wisconsin, 2015 Linden Dr. West, Madison, WI 53706 USA, Mitchell@svm.vetmed.wisc.edu, TEL: 608-263-9826.

${ }_{3}^{3}$ Present address: Department of Natural and Physical Science, 2050 Highway 501 East, Conway, SC 29528

${ }_{5}^{4}$ Present address: Boston Biomedical Research Institute, 64 Grove Street, Watertown, MA 02472

5 Present address: Faculty of Biotechnology, Madison College, Madison, WI 53704

Publisher's Disclaimer: This is a PDF file of an unedited manuscript that has been accepted for publication. As a service to our customers we are providing this early version of the manuscript. The manuscript will undergo copyediting, typesetting, and review of the resulting proof before it is published in its final citable form. Please note that during the production process errors may be discovered which could affect the content, and all legal disclaimers that apply to the journal pertain. 
Limited spontaneous recovery of respiratory function below a $\mathrm{C}_{2}$ cervical hemisection $\left(\mathrm{C}_{2} \mathrm{HS}\right)$ occurs in short and long time domains. Within 4 hours post- $\mathrm{C}_{2} \mathrm{HS}$, morphological changes are observed in bulbospinal and propriospinal synapses onto phrenic motor neurons, and these morphological changes persist at least 4 days post-injury (Goshgarian et al., 1989). Spontaneous functional recovery of hemidiaphragm EMG and ipsilateral phrenic nerve output is observed six weeks post- $\mathrm{C}_{2} \mathrm{HS}$, largely due to strengthening of a latent crossedspinal synaptic pathway (Nantwi et al., 1999; Goshgarian, 2003). Following partial spontaneous recovery of respiratory motor output below a cervical hemisection (Goshgarian, 2003), there is at least some capacity to induce additional phrenic motor plasticity, enhancing the spontaneous functional recovery. For example, four weeks post- $\mathrm{C}_{2} \mathrm{HS}$, acute intermittent hypoxia induces phrenic long-term facilitation ipsilateral to injury (Golder and Mitchell, 2005). However, mechanisms leading to spontaneous or induced respiratory plasticity following $\mathrm{C}_{2} \mathrm{HS}$ are not completely known, particularly mechanisms contributing to the maintenance of long-lasting functional recovery.

One molecule that may contribute to respiratory plasticity after $\mathrm{C}_{2} \mathrm{HS}$ is the atypical PKC (aPKC) isoform, PKM $\zeta$. This truncated isoform of PKC $\zeta$ contains only the catalytic domain and is constitutively active (Takai et al., 1977; Inoue et al., 1977). PKM $\zeta$ is essential for the maintenance of long-term memory and hippocampal long-term potentiation (Ling et al., 2002; Pastalkova and Serrano et al., 2006).

Atypical PKCs are expressed in phrenic motor neurons and, possibly, nearby interneurons (Guenther et al., 2010a), key sites for spinal respiratory motor plasticity (Mitchell et al., 2001; Fuller et al., 2000; Lane et al., 2008). We hypothesize that aPKCs in or near phrenic motor neurons increase expression and activity after $\mathrm{C}_{2} \mathrm{HS}$, suggesting the possibility of a role in long-lasting functional recovery. To test this hypothesis, we analyzed aPKC expression and activity in ventral spinal segments $\mathrm{C}_{3-5} 1,3$, and 28 days following $\mathrm{C}_{2} \mathrm{HS}$. Three methods were utilized: 1) aPKC activity assays; 2) immunoblots to compare aPKC isoform expression (PKC , $\mathrm{PKM} \zeta$, and $\mathrm{PKC}$ ); and 3) immunohistochemistry to localize aPKC expression in presumptive phrenic motor neurons (vs. glia). These data were presented in preliminary form (Guenther et al., 2010b).

\section{METHODS}

Animals

All experimental procedures were approved by the Animal Care and Use Committee in the School of Veterinary Medicine, University of Wisconsin. A total of 42 adult male Lewis rats were used in this study (3-6 months of age, Harlan, Indianapolis IN, Colony 202A).

\section{Spinal Surgery}

26 rats were pretreated with $1.0 \mathrm{ml}$ of a solution containing an analgesic (buprenorphine, 50 $\mu \mathrm{g} / \mathrm{kg}$, s.c.), an anti-inflammatory drug (carprofen, $5 \mathrm{mg} / \mathrm{kg}$, s.c.), an antibiotic (enrofloxacin, $4 \mathrm{mg} / \mathrm{kg}$, s.c.) and a sedative (dexmedetomidine, $100 \mu \mathrm{g} / \mathrm{kg}$, s.c.) in lactated Ringer's solution. Anesthesia was induced in a closed chamber with 5\% isoflurane in oxygen. Rats were intubated and anesthesia was maintained (1.5\% isoflurane in 100\% oxygen) while mechanically ventilated. Skin and muscle above spinal segments $\mathrm{C}_{2-3}$ were retracted to expose the vertebrae. In sham rats, a $\mathrm{C}_{2}$ laminectomy and durotomy were performed and the wound was closed. In $\mathrm{C}_{2} \mathrm{HS}$ rats, the laminectomy and durotomy were followed by left $\mathrm{C}_{2}$ hemisection via aspiration with a 23 -gauge blunt needle.

Muscle and skin were sutured closed, and an agent to reverse the dexmedetomidine sedative (atipamezole, $500 \mu \mathrm{g} / \mathrm{kg}$, i.m.) was injected. Rats were treated for 2 days with $1.0 \mathrm{ml}$ of a solution containing buprenorphine ( $50 \mu \mathrm{g} / \mathrm{kg}$, s.c.), carprofen $(5 \mathrm{mg} / \mathrm{kg}$, s.c.) and 
enroflaxacin ( $4 \mathrm{mg} / \mathrm{kg}$, s.c.) in lactated Ringer's solution. Three post-injury recovery times were tested: 1 day ( $n=4$ sham, $\left.n=4 C_{2} \mathrm{HS}\right), 3$ days $\left(n=4\right.$ sham, $\left.n=4 \mathrm{C}_{2} \mathrm{HS}\right)$ and 28 days $(n=5$ sham, $n=5 \mathrm{C}_{2} \mathrm{HS}$ ). Five additional rats without surgery were sacrificed as a naïve control group.

\section{Tissue Preparation}

All rats were anesthetized with isoflurane and euthanized with an overdose of BeuthanasiaD (Schering-Plough, Netherlands, pentobarbital, at least $120 \mathrm{mg} / \mathrm{kg}$, i.c.). $\mathrm{C}_{1-2}$ was rapidly removed and post-fixed in $4 \%$ paraformaldehyde solution overnight at $4{ }^{\circ} \mathrm{C}$. Fixed $\mathrm{C}_{1-2}$ tissues were cryoprotected in $30 \%$ sucrose solution in PBS. $\mathrm{C}_{3-5}$ spinal segments were harvested and immediately placed on dry ice. The dorsal half of the spinal cord and the ventral white matter of $\mathrm{C}_{3-5}$ were removed, and the ventral gray matter was divided into ipsi- and contralateral sides. The ipsi- and contralateral $\mathrm{C}_{3-5}$ segments were homogenized in buffer (in mM: 15 Hepes, $10 \mathrm{KCl}, 5 \mathrm{MgCl}_{2}, 0.1$ EDTA, 0.5 EGTA, 1 DTT, $1 \mathrm{Na}_{3} \mathrm{VO}_{4}$, $\mathrm{pH}=7.5$ ) with $1 \mathrm{mM}$ PMSF and protease inhibitor cocktail (Roche Applied Science, Indianapolis IN). Protein concentration was determined by Biorad's protein microassay (500-0006, Bio-Rad, Hercules, CA), and samples were normalized to lowest protein concentration. Samples were divided into aliquots for aPKC enzyme activity assay and Western Blot analysis.

\section{Extent of Injury}

Fixed $\mathrm{C}_{1-2}$ tissues were sectioned with a sliding microtome into $40 \mu \mathrm{m}$ thick longitudinal sections. Representative sections were taken throughout the spinal cord and stained with Cresyl Violet. A Nikon Eclipse E600 microscope was used to determine the extent of injury relative to midline. A coronal reconstruction of the injury was created based on these sections (Figure 1). All $\mathrm{C}_{2}$ segments are represented except a single rat from the 1 day postinjury group because our attempt at removing the $C_{2}$ spinal segment was not successful. However, we included this rat in the analyses because documented $\mathrm{C}_{2}$ hemisections were relatively consistent, and there was no reason to question this sample based on activity assays or immunoblots.

\section{Activity Assays}

Homogenized ipsi- and contralateral $\mathrm{C}_{3-5}$ segments extracts were combined with assay reagents for a $20 \mu \mathrm{L}$ total reaction containing $\sim 2 \mu \mathrm{g}$ of homogenized extracts (varied slightly to standardize proteins), $20 \mathrm{mM}$ Tris, $200 \mathrm{mM} \mathrm{NaCl}$, and $\gamma^{32} \mathrm{P}$ ATP (Perkin Elmer, Waltham, MA, USA, $0.5 \mu \mathrm{Ci}$ ). For each sample, the experiment was run with (to measure aPKC activity) and without (baseline enzyme activity) $\mathrm{PKC} \varepsilon$ substrate peptide (Millipore, Billerica, MA, $25 \mu \mathrm{M}$ resuspended in water). The reaction was run for $15 \mathrm{~min}$ at $30^{\circ} \mathrm{C}$ and stopped with EDTA ( $10 \mu \mathrm{L}$ of $500 \mathrm{mM}$ containing bromophenol blue dye). Samples were spotted onto p81 phosphocellulose filters (Millipore, Billerica, MA). After drying for $5 \mathrm{~min}$, filters were washed several times with 5\% acetic acid. A final wash with $95 \%$ ethanol was performed before drying for 5 min on Whatman paper. Individual filters were placed in scintillation fluid and counts measured. Each reaction was run in triplicate.

\section{Western immunoblot}

Procedures were similar to our previous publication (Guenther et al., 2010a). Sample buffer was added to homogenized samples and heated for $5 \mathrm{~min}$ at $95^{\circ} \mathrm{C}$. These samples were loaded onto 4-20\% gradient polyacrylamide gels (Bio-Rad, Hercules, CA). Protein was transferred to Immobilon polyvinylidene difluoride membranes (Millipore, Billerica MA). Blots were blocked in TBST (20mM Tris, $500 \mathrm{mM} \mathrm{NaCl}, 0.1 \%$ Tween) with $6 \%$ milk (blocking buffer) for 1 hour and probed with primary antibody (PKC $\zeta / \imath$, Santa Cruz C-20; 
phospho-PKC $/ 2$, Epitomics; or $\mathrm{PKC \imath}, \mathrm{BD}$ labs; refer to Table 1 for details on antibodies) in blocking buffer overnight at $4^{\circ} \mathrm{C}$. Immunoblots were rinsed in TBST and probed with HRP-conjugated mouse anti-rabbit IgG (for $\mathrm{PKC} \zeta / \imath$ and phospho-PKC $\zeta / \imath$ ) or HRPconjugated donkey anti-mouse IgG (for PKC $\imath$ ) secondary antibodies (Jackson Immuno, West Grove PA, 1:10,000) for 1 hour at room temperature. The immunoblot label was expressed using Super Signal West Dura extended duration chemiluminescent kit (Pierce Biotechnology, Rockford, IL). Chemiluminescence was detected and digitized using an AutoChemi imaging system with LabWorks 4.6 (UVP Bioimaging Systems, Upland, CA). Blots were stripped using Restore Western blot Stripping Buffer (Pierce Biotechnology, Rockford IL) and re-probed with GAPDH. Selected blots were stained for total protein (Biosafe Coomassie stain, Bio-Rad, Hercules, CA) after immunoblot to confirm equal protein loading.

\section{Immunofluorescence}

Sham ( $\mathrm{n}=5$ ) or $\mathrm{C}_{2} \mathrm{HS}$ ( $\mathrm{n}=6$ ) surgeries were performed on different rats, which were perfused with $4 \%$ paraformaldehyde 28 days post-surgery. Spinal segments $\mathrm{C}_{1-3}$ and $\mathrm{C}_{4-6}$ were

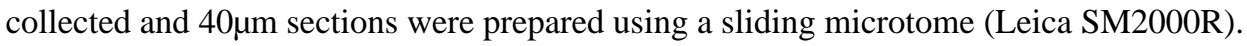
Sections from the site of injury were visualized with Cresyl Violet to confirm the extent of injury as described previously. For immunohistochemistry, coronal sections taken from spinal segments $\mathrm{C}_{4-5}$ were stained from each animal ( $\mathrm{n}=11$ rats; see Table 1$)$. Sections were labeled with antibody raised against protein kinase C $\zeta$ (1:1000 PKC $\zeta / \imath$ C-20, Santa Cruz Biotechnology). Sections were co-stained with antibodies raised against CD11b (1:100 OX42, Santa Cruz Biotechnology) and GFAP (1:1000 AB5541, Millipore) to detect colocalization of PKC $\zeta$ with microglia and astrocytes, respectively. All secondary antibodies were conjugated to Alexa Fluor® fluorescent dyes (Invitrogen, Carlsbad, CA, USA). Sections were mounted on slides with VectaShield Hardset (Vector Laboratories, UK).

\section{Data analysis}

For activity assays and immunoblots, data were expressed as a percent change from: 1) the time-matched sham/ipsilateral group, or 2) the sham/ipsilateral group average 1 day postsurgery. For immunoblot analysis of aPKC and phosphorylated aPKC, duplicate measurements from each sample were averaged. For activity assays, values in which the background level of enzyme activity was greater than the signal due to aPKC activity were omitted from analysis. A three-way repeated measures ANOVA (surgery, side relative to injury, and time) was run using SPSS (IBM, Chicago, IL). For activity assays and immunoblot analysis, a two-way repeated measures ANOVA (surgery and side relative to injury) within each time point of recovery was run using SigmaStat 2.03 (Systat, Chicago, IL), with individual comparisons made based on Fisher's LSD post hoc test. Multiple regression analyses were used to assess correlations of aPKC isoform expression with aPKC activity using SigmaStat 2.03 (Systat, Chicago, IL). Differences were considered significant if $\mathrm{p}<0.05$. Values are reported as means \pm 1 SEM.

All immunofluorescence was imaged with a Nikon C1 confocal imaging system with EZ-C1 confocal imaging software (Nikon, Japan); $2 \mu \mathrm{m}$ step increments were used for the $\mathrm{z}$-series. Regions of interest were chosen for imaging with a 40x Plan Apo objective by selecting areas in the ventrolateral portion of the $\mathrm{C}_{4-5}$ ventral horn containing large, presumptive phrenic motor neurons. All images were collected with the same laser and EZ-C1 software settings to eliminate potential user artifacts. Z-series images were created with the "Rocking 3D Project" plug-in in ImageJ (NIH, Bethesda, MD) and intensity adjusted using Photoshop CS3 (Adobe, San Jose, CA). Histogram data were preserved with the Photoshop adjustments applied. 


\section{RESULTS}

\section{Characterization of the injury}

Reconstruction of the lesion at spinal segment $\mathrm{C}_{2}$ revealed that most animals had a near complete hemisection, extending to the midline (Figure 1). Only one animal in the 3 day recovery group had a lesion extending into the contralateral side (Figure 1C). However, we included this rat in analysis because the injury did not extend into the contralateral white matter, and there was no reason to question this sample based on activity assays or immunoblots.

\section{Atypical PKC activity increases following $\mathrm{C}_{2} \mathrm{HS}$}

Atypical PKC activity was elevated 1 and 28, but not 3 days post- $\mathrm{C}_{2} \mathrm{HS}$ (Figure 2). On day 1 post-C2HS, aPKC activity increased more than $50 \%$ ipsilateral to injury ( $\mathrm{p}=0.026 \mathrm{vs}$. sham); similar effects were not observed contralateral to $\mathrm{C}_{2} \mathrm{HS}$ (Figure $2 \mathrm{~A}$ ). On day 3 post- $\mathrm{C}_{2} \mathrm{HS}$, aPKC activity was unchanged relative to sham rats on either side of the spinal cord ( $p>0.05$; Figure 2B). On day 28 post- $\mathrm{C}_{2} \mathrm{HS}$, overall aPKC activity is significantly higher in $\mathrm{C}_{2}$ hemisected v. sham rats, regardless of side $(\mathrm{p}=0.011)$. This increase arose from greater aPKC activity contralateral to $\mathrm{C}_{2} \mathrm{HS}$ ( $\mathrm{p}=0.018$ ); an apparent increase ipsilateral to injury was only marginally significant ( $\mathrm{p}=0.096$; Figure $2 \mathrm{C}$ ). Overall, aPKC activity 28 days postinjury is significantly greater than 1 day post-injury (three-way, repeated measures ANOVA, $\mathrm{p}=0.015$; Figure 2D).

\section{PKM 3 expression increases following $\mathrm{C}_{2} \mathrm{HS}$}

Total PKM $\zeta$ protein levels increased significantly at 28 , but not 1 or 3 days post- $\mathrm{C}_{2} \mathrm{HS}$ (Figure 3). One day post- $\mathrm{C}_{2} \mathrm{HS}, \mathrm{PKM} \zeta$ was significantly higher ipsilateral versus contralateral to injury $(\mathrm{p}=0.012)$, although there were no individually significant effects on either side relative to sham rats ( $p>0.05$; Figure $3 \mathrm{~A}$ ). 28 days post-injury, PKM $\zeta$ expression is significantly increased ipsilateral $\left(\mathrm{C}_{2} \mathrm{HS} \mathrm{v}\right.$. sham, $\left.\mathrm{p}=0.011\right)$, but not contralateral to injury (ipsi v. contra, $\mathrm{p}=0.020$; Figure $3 \mathrm{C}$ ). $\mathrm{PKC} \zeta /$ expression did not change significantly at any time post-injury ( $\mathrm{p}>0.05$, Figure 3$)$.

\section{Phosphorylated PKM}

Phosphorylated PKM $\zeta$ protein levels increased significantly at 28 days post- $\mathrm{C}_{2} \mathrm{HS}$ (Figure 4). 28 days post $-\mathrm{C}_{2} \mathrm{HS}$, phosphorylated $\mathrm{PKC} / \imath$ protein levels were significantly higher ipsilateral versus contralateral to injury $(\mathrm{p}=0.012)$, although there were no individually significant effects on either side relative to sham rats ( $>0.05$; Figure 4A). Phosphorylated PKM $\zeta$ was significantly increased 28 days post-C2HS ipsilateral (C2HS vs. sham, $\mathrm{p}=0.022$ ), but not contralateral to injury (ipsi vs. contra, $\mathrm{p}=0.003$; Figure $4 \mathrm{~B}$ ). There were no significant differences in phosphorylated $\mathrm{PKC} \zeta / \imath$ or PKM $\zeta$ at any other time points tested ( $>0.05$, not shown).

\section{Linear regression analysis}

Multivariate regression analysis indicated significant correlations between aPKC enzyme activity and PKC $\mathrm{P}$ expression $\left(\mathrm{r}^{2}=0.102, \mathrm{p}=0.021\right)$, as well as with PKM $\zeta$ and $\mathrm{PKC \imath}$ $\left(\mathrm{r}^{2}=0.188, \mathrm{p}=0.006\right)$ when using data from both ipsi- and contralateral sides relative to injury (Table 2). However, the correlation was stronger when data exclusively from the side of injury were used, including significant contributions to the regression from PKC $\zeta / 2$, PKM $\zeta$ and $\mathrm{PKC \imath}\left(\mathrm{r}^{2}=0.675, \mathrm{p}<0.001\right.$, Table 3$)$. Similar regressions were considerably less robust when data exclusively from the side contralateral to injury were used ( $p>0.05$, Table 4 ). 


\section{Immunohistochemical localization of atypical PKCs in presumptive phrenic motor neurons}

Atypical PKCs were expressed in large, presumptive phrenic motor neurons in the ventral horn of spinal segments $\mathrm{C}_{4-5}$ in both sham and $\mathrm{C}_{2}$ hemisected rats (Figure 5). The lack of apparent co-localization of aPKCs with markers for astrocytes (GFAP) and microglia (OX-42) suggests that atypical PKC expression is minimal in glia within the phrenic motor nucleus (Figure 5). $\mathrm{C}_{2} \mathrm{HS}$ had no effects on aPKC distribution among these cell types, at least 28 days post-injury.

\section{DISCUSSION}

Atypical PKC enzymatic activity and expression in the ventral cervical spinal cord are affected 1 and 28 days post- $\mathrm{C}_{2} \mathrm{HS}$, providing suggestive evidence that aPKC isoforms may play an important role in acute and longer-lasting responses to spinal injury. The transient return of aPKC expression and activity to control levels 3 days post-injury suggests the possibility of differing roles in short-term versus long-term recovery from $\mathrm{C}_{2} \mathrm{HS}$. Since PKC $\zeta$ has been implicated in inflammatory pathways through TNF-a signaling (Müller et al., 1995) and long-term hippocampal plasticity (Ling et al., 2002), we suggest the possibility that changes in aPKC expression and activity post- $\mathrm{C}_{2} \mathrm{HS}$ relate to short-term inflammatory responses ( 1 day) and long-term respiratory motor plasticity (28 days), respectively. Over longer recovery periods ( 28 days), increased aPKC levels may maintain spinal respiratory plasticity that underlies partial, spontaneous functional recovery following $\mathrm{C}_{2} \mathrm{HS}$ (cf. Goshgarian, 2003).

Changes in aPKC activity ipsilateral v. contralateral to injury are time-dependent (Figure 2), with bilateral increases after 28 days, but only ipsilateral increases 1 day post- $\mathrm{C}_{2} \mathrm{HS}$. "Crosscorrelation" analysis of ipsilateral and contralateral phrenic neurograms has been used to demonstrate common activation pathways on both sides of the spinal cord (Sandhu et al., 2009). However, whereas correlogram peaks were not observed 2 weeks post- $\mathrm{C}_{2} \mathrm{HS}$, they were observed in half of the rats at 12 weeks post $-\mathrm{C}_{2} \mathrm{HS}$. Since the time course of phrenic motor plasticity may differ ipsilateral v. contralateral to injury, similar differences in the temporal pattern may be expected in aPKC activity.

Immunohistochemical analysis identified aPKC protein in presumptive phrenic motor neurons at spinal segment $\mathrm{C}_{4} 28$ days post- $\mathrm{C}_{2} \mathrm{HS}$, but not in surrounding glia. This localization pattern is similar to previous findings from our laboratory demonstrating aPKC protein expression in identified phrenic motor neurons and possibly interneurons, but not in adjacent glia (Guenther et al., 2010a). Here we demonstrate that, as protein expression increases, cellular localization of aPKCs does not qualitatively change following $\mathrm{C}_{2} \mathrm{HS}$, at least 28 days post-injury. Thus, aPKCs may play a particularly important role within phrenic (and other) motor neurons.

Multiple linear regression analyses suggest that PKM $\zeta$ and PKC $\imath$ protein levels are most strongly correlated with aPKC activity, and that this relationship is most apparent ipsilateral to injury (Tables 2 and 3). Thus, aPKC protein expression predicts enzymatic activity and, possibly, inflammation and/or functional recovery following $\mathrm{C}_{2} \mathrm{HS}$.

\section{Methodological Limitations}

Although the PKC $\varepsilon$ substrate peptide used in aPKC activity assays is reported to be specific for aPKCs (Nunbhakdi-Craig et al., 2002), it may serve as a substrate for all PKC isoforms and the enzyme MST2. MST2 mRNA is expressed in very low levels in human brain tissue (Creasy and Chernoff, 1995), and there are no reports concerning its presence in spinal cord. Three families of PKCs are distinguished based on structure and second messenger signaling. The conventional PKCs require calcium and diacylglycerol for activation, the 
novel PKCs require diacylgylcerol for activation, and the aPKCs are regulated by a second messenger system requiring neither calcium nor diacylglycerol (Nishizuka, 1995). Since activity assays in the present study were performed on tissues homogenized with calcium chelators (EDTA and EGTA), and diacylglycerol was not added to the reaction, it is unlikely that novel or conventional PKCs contribute significantly to measured activity (Koide et al., 1992). Elevated diacylglycerol levels have been reported in thoracic spinal cord after contusion injuries, but levels peaked 6 hours post-injury (Murphy et al., 1994). Since all measurements in our study were taken $>1$ day post-injury, measured enzymatic activity most likely reflects aPKC isoforms.

Although specific antibodies for each atypical PKC isoform would enable us to distinguish their activity through immunoprecipitation studies, it is difficult to find reliable antibodies that react exclusively with PKM $\zeta$ v. full-length PKC $\zeta$ (the C-terminus is identical). Therefore, we utilized western immunoblots with global atypical PKC antibodies to examine isoform expression based on molecular weight $\mathrm{v}$. antibody specificity.

For immunoblot analysis, loading controls, such as actin or $\beta$-tubulin are frequently used to ensure equivalent loading across the gel. However, it is difficult to find suitable loading controls in studies of spinal injury since frequently used proteins also change expression (Vinit et al., 2009), including GAPDH (shown here). Thus, we standardized homogenates based on total protein levels measured with the Biorad protein microassay, with no further attempt to normalize the data presented here. There is debate on whether using loading controls is always appropriate since an inappropriate choice of the loading control protein alters the question of interest (Aldridge et al., 2008). Coomassie staining post-analysis confirmed qualitatively equal protein loading across selected blots (see methods).

\section{Possible functions of elevated aPKC}

Although this study speaks only to neurochemical plasticity following $\mathrm{C}_{2} \mathrm{HS}$, possible physiological functions of elevated aPKC can be suggested based on literature reports. For example, aPKC activity is critical for a recently reported form of respiratory plasticity referred to as inactivity-induced phrenic motor facilitation (Broytman et al., 2010). Phrenic inactivity increases $\mathrm{TNFa}$ in ventral spinal homogenates that include the phrenic motor nucleus (Strey et al., 2010), thus suggesting a link between pro-inflammatory cytokines and aPKC-dependent respiratory plasticity. TNFa activation is coupled with PKC $\zeta$ activity in vitro, largely due to TNFa-induced ceramide production. Whereas low levels of TNFainduced ceramide production promote PKCS activity, high TNFa-induced ceramide or arachidonic acid levels inhibit PKCS activity (Müller et al., 1995). Studies on PKCS knockout mice support a role for PKCS in NFkB activation downstream of TNFa. Although the mechanism of NFKB activation is unclear, PKCS may directly phosphorylate the p65 subunit of NFKB, increasing transcriptional activity. Alternately, PKC $\zeta$ may phosphorylate the IKK complex, thereby releasing NFkB and allowing translocation to the nucleus (Leitges et al., 2001). Short-term aPKC activity increases following $\mathrm{C}_{2} \mathrm{HS}$ may reflect these early, cytokine related processes.

Since PKM $\zeta$ plays a critical role in the maintenance of hippocampal long-term potentiation and long-term memory (Ling et al., 2002; Pastalkova and Serrano et al., 2006), increased aPKC activity 28 days post- $\mathrm{C}_{2} \mathrm{HS}$ may reflect an important role in long-lasting plasticity and functional recovery following cervical spinal injury.

\section{Conclusions}

Atypical PKC activity is elevated 1 and 28, but not 3 days post- $\mathrm{C}_{2} \mathrm{HS}$. Ipsilateral to injury, increased aPKC activity correlates strongly with all atypical isoforms (PKC $\zeta / \imath, \mathrm{PKM} \zeta$, and 
$\mathrm{PKC}$ ), suggesting that all isoforms contribute to the aPKC activity response following spinal injury. Atypical PKC isoforms are detected in large, presumptive phrenic motor neurons, but not in adjacent glia 28 days post- $\mathrm{C}_{2} \mathrm{HS}$. Given aPKC's localization in the phrenic motor nucleus, and differential expression following $\mathrm{C}_{2} \mathrm{HS}$, aPKCs may contribute to: 1) an early inflammatory response that may initiate spontaneous plasticity, and/or 2) long-lasting spinal respiratory plasticity that maintains functional recovery following cervical spinal injury.

\section{Highlights}

1. Cervical spinal injury increases atypical PKC activity in the phrenic motor nucleus.

2. PKMzeta is the major atypical PKC isoform increased by cervical spinal injury.

3. Atypical PKC's are expressed in neurons and not glia following cervical injury.

4. Atypical PKC may contribute to recovery of breathing capacity after cervical injury.

\section{Acknowledgments}

This work was supported by National Institutes of Health grants HL69064 HL80209 and NS063245, AHAF grant A2009044, and training grants NIH T32 HL007654 and T32-GM007507. The authors wish to thank Dr. Stéphane Vinit for assistance in reconstructing the lesion sites, and Dr. Tracy Baker-Herman for her critique of the manuscript.

\section{REFERENCES}

Aldridge GM, Podrebarac DM, Greenough WT, Weiler IJ. The use of total protein stains as loading controls: an alternative to high-abundance single protein controls in semi-quantitative immunoblotting. J Neurosci Methods. 2008; 172:250-254. [PubMed: 18571732]

Broytman O, Strey KA, Baker-Herman TL. Differential regulation of ventral spinal atypical PKC and ERK MAP kinase following hypocapnia-induced respiratory neural inactivity. FASEB J. 2010; 24:799.7. (abstract). [PubMed: 19897662]

Creasy CL, Chernoff J. Cloning and characterization of a member of the MST subfamily of Ste20-like kinases. Gene. 1995; 167:303-306. [PubMed: 8566796]

Dale-Nagle EA, Hoffman MS, MacFarlane PM, Satriotomo I, Lovett-Barr MR, Vinit S, Mitchell GS. Spinal plasticity following intermittent hypoxia: implications for spinal injury. Ann. N.Y. Acad. Sci. 2010; 1198:252-259. [PubMed: 20536940]

Fuller DD, Bach KB, Baker TL, Kinkead R, Mitchell GS. Long term facilitation of phrenic motor output. Respir Physiol. 2000; 121:135-146. [PubMed: 10963770]

Golder FJ, Mitchell GS. Spinal synaptic enhancement with acute intermittent hypoxia improves respiratory function after chronic cervical spinal cord injury. J Neurosci. 2005; 25:2925-2932. [PubMed: 15772352]

Goshgarian HG, Yu XJ, Rafols JA. Neuronal and glial changes in the rat phrenic nucleus occurring within hours after spinal cord injury. J Comp Neurol. 1989; 284:519-533. [PubMed: 2768550]

Goshgarian HG. The crossed phrenic phenomenon: a model for plasticity in the respiratory pathways following spinal cord injury. J Appl Physiol. 2003; 94:795-810. [PubMed: 12531916]

Guenther CH, Vinit S, Windelborn JA, Behan M, Mitchell GS. Atypical protein kinase C expression in phrenic motor neurons of the rat. Neuroscience. 2010a; 169:787-793. [PubMed: 20478365]

Guenther CH, Tubon TC, Windelborn JA, Yin JCP, Mitchell GS. Alterations in atypical PKC expression and activity near the phrenic motor nucleus following cervical spinal injury. FASEB J. 2010b; 24:643.1. (abstract). 
Inoue M, Kishimoto A, Takai Y, Nishizuka Y. Studies on a cyclic nucleotide-independent protein kinase and its proenzyme in mammalian tissues: II. Proenzyme and its activation by calciumdependent protease from rat brain. J Biol Chem. 1977; 252:7610-7616. [PubMed: 199594]

Koide H, Ogita K, Kikkawa U, Nishizuka Y. Isolation and characterization of the $\varepsilon$ subspecies of protein kinase C from rat brain. Proc Natl Acad Sci. 1992; 89:1149-1153. [PubMed: 1741371]

Lane MA, White TE, Coutts MA, Jones AL, Sandhu MS, Bloom DC, Bolser DC, Yates BJ, Fuller DD, Reier PJ. Cervical prephrenic interneurons in the normal and lesioned spinal cord of the adult rat. J Comp Neurol. 2008; 511:692-709. [PubMed: 18924146]

Leitges M, Sanz L, Martin P, Duran A, Braun U, García JF, Camacho F, Diaz-Meco MT, Rennert PD, Moscat J. Targeted disruption of the $\zeta$ PKC gene results in the impairment of the NF- $\kappa$ B pathway. Mol Cell. 2001; 8:771-780. [PubMed: 11684013]

Ling DS, Bernardo LS, Serrano PA, Blace N, Kelly MT, Crary JF, Sacktor JTC. Protein kinase MS is necessary and sufficient for LTP maintenance. Nat Neurosci. 2002; 5:295-296. [PubMed: 11914719]

Mitchell GS, Baker TL, Nanda SA, Fuller DD, Zabka AG, Hodgeman BA, Bavis RW, Mack KJ, Olson EB Jr. Intermittent hypoxia and respiratory plasticity. J Appl Physiol. 2001; 90:2466-2475. [PubMed: 11356815]

Mitchell, GS. Respiratory plasticity following intermittent hypoxia: a guide for novel therapeutic approaches to ventilatory control disorders. In: Gaultier, C., editor. Genetic Basis for Respiratory Control Disorders. New York: Springer Publishing Company; 2007. p. 291-311.

Müller G, Ayoub M, Storz P, Rennecke J, Fabbro D, Pfizenmaier K. PKC $\zeta$ is a molecular switch in signal transduction of TNF-a, bifunctionally regulated by ceramide and arachidonic acid. EMBO J. 1995; 14:1961-1969. [PubMed: 7744003]

Murphy EJ, Behrmann D, Bates CM, Horrocks LA. Lipid alterations following impact spinal cord injury in the rat. Mol Chem Neuropathol. 1994; 23:13-26. [PubMed: 7893328]

Nantwi KD, El-Bohy AA, Schrimsher GW, Reier PJ, Goshgarian HG. Spontaneous functional recovery in a paralyzed hemidiaphragm following upper cervical spinal cord injury in adult rats. Neurorehabil Neural Repair. 1999; 13:225-234.

Nishizuka Y. Protein kinase C and lipid signaling for sustained cellular responses. FASEB J. 1995; 9:484-496. [PubMed: 7737456]

Nunbhakdi-Craig V, Machleidt T, Ogris E, Belloto D, White CL III, Sontag E. Protein phosphatase 2A associates with and regulates atypical PKC and the epithelial tight junction complex. J Cell Biol. 2002; 158:967-978. [PubMed: 12196510]

Pastalkova E, Serrano P, Pinkhasova D, Wallace E, Fenton AA, Sactor TC. Storage of spatial information by the maintenance mechanism of LTP. Science. 2006; 313:1141-1144. [PubMed: 16931766]

Sandhu MS, Dougherty BJ, Lane MA, Bolser DC, Kirkwood PA, Reier PJ, Fuller DD. Respiratory recovery following high cervical hemisection. Respir Physiol Neurobiol. 2009; 169:94-101. [PubMed: 19560562]

Strey KA, Broytman O, Baker-Herman TL. Increased ventral spinal TNF-alpha following hypocapniainduced respiratory neural inactivity. FASEB J. 2010; 24:799.6. (abstract). [PubMed: 19897662]

Takai Y, Kishimoto A, Inoue M, Nishizuka Y. Studies on a cyclic nucleotide-independent protein kinase and its proenzyme in mammalian tissues: I. Purification and characterization of an active enzyme from bovine cerebellum. J Biol Chem. 1977; 252:7603-7609. [PubMed: 199593]

Vinit S, Darlot F, Stamegna JC, Gauthier P, Kastner A. Effect of cervical spinal cord hemisection on the expression of axon growth markers. Neurosci Lett. 2009; 462:276-280. [PubMed: 19559075]

Vinit S, Lovett-Barr MR, Mitchell GS. Intermittent hypoxia induces functional recovery following cervical spinal injury. Respir. Physiol. \& Neurobiol. 2009; 169:210-217. [PubMed: 19651247]

Winslow C, Rozovsky J. Effect of spinal cord injury on the respiratory system. Am J Phys Med Rehabil. 2003; 82:803-814. [PubMed: 14508412] 
A

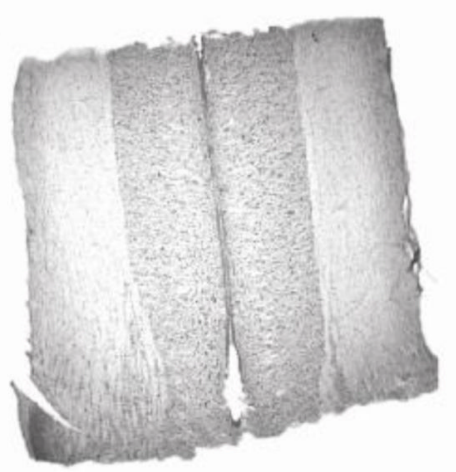

B

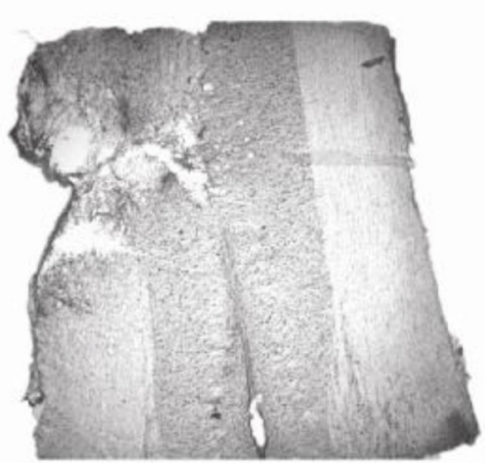

\section{C}

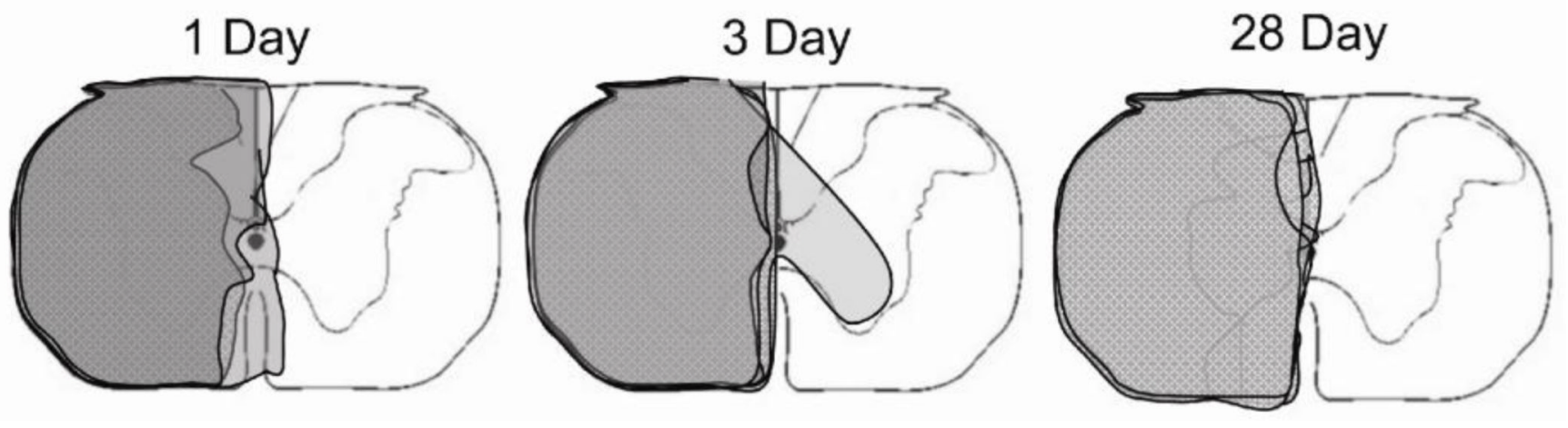

Figure 1.

Extent of $\mathrm{C}_{2} \mathrm{HS}$ injuries. Cresyl Violet stained longitudinal section of spinal cord segment $\mathrm{C}_{2}$ around the central canal in a sham operated rat (A) and $\mathrm{C}_{2}$ hemisected rat (B). (C) Coronal reconstruction of all $\mathrm{C}_{2}$ segments from hemisected rats according to time of recovery. 
A

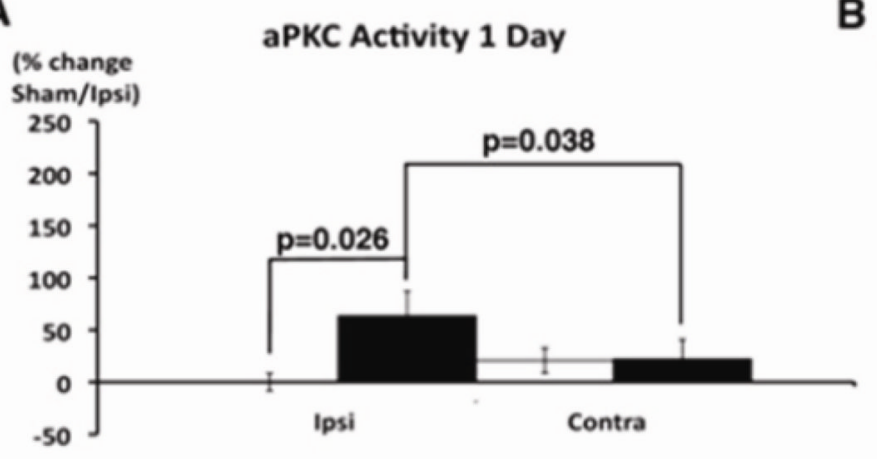

B

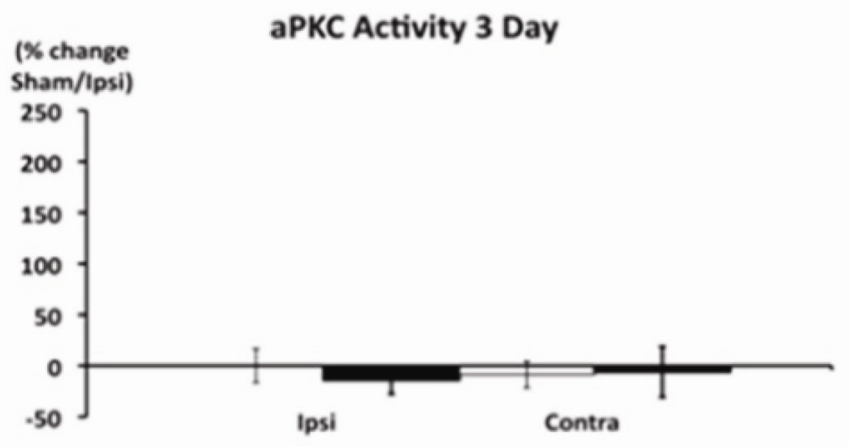

C

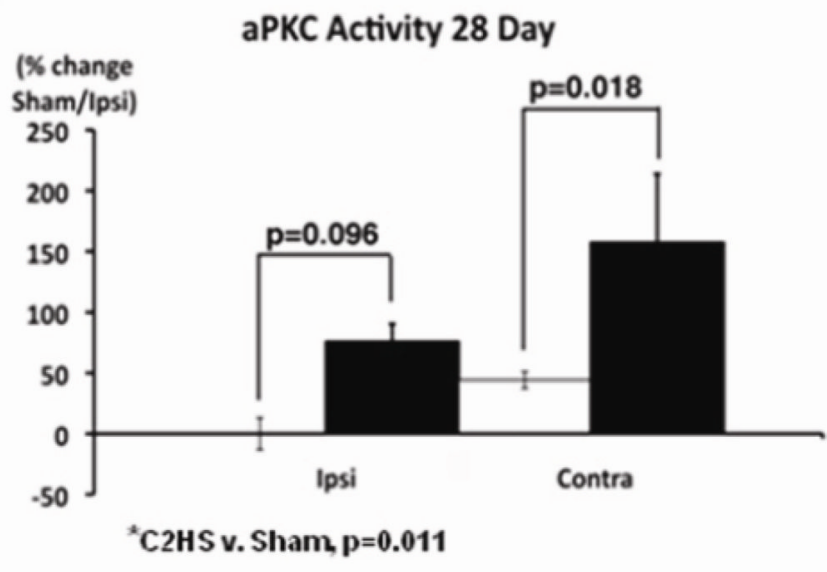

D

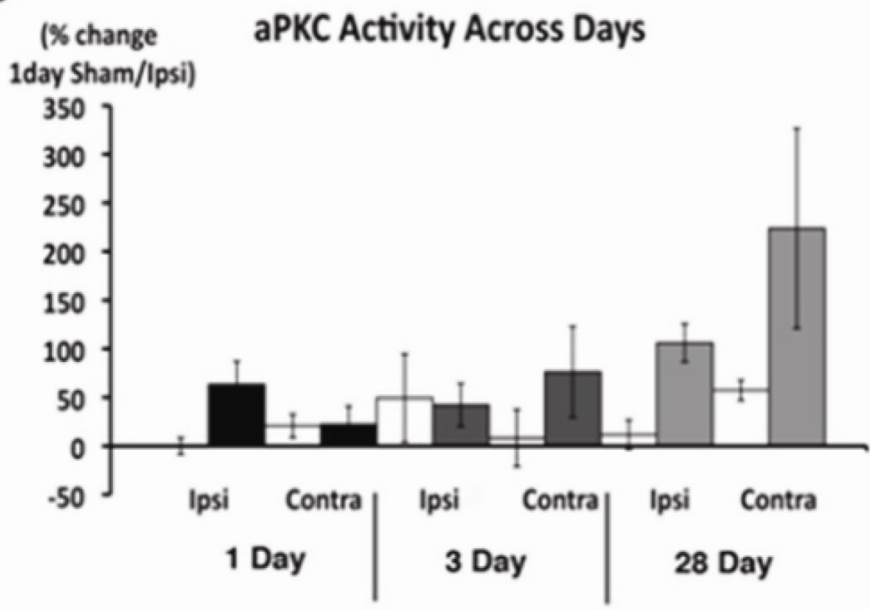

Figure 2.

Atypical PKC enzyme activity is elevated in the phrenic motor nucleus 1 and 28 days post$\mathrm{C}_{2}$ hemisection. Atypical PKC activity was measured in ventral $\mathrm{C}_{3-5}$ homogenates either ipsi- or contralateral to injury from sham (white bar) and $\mathrm{C}_{2}$ hemisection (black bar). (A) After one day of recovery, aPKC activity is significantly increased on the side ipsilateral to injury $\left(\mathrm{C}_{2} \mathrm{HS}\right.$ v. sham, $\mathrm{p}=0.026$; ipsi vs. contra, $\left.\mathrm{p}=0.038\right)(\mathrm{B})$ Three days post-injury, there is no significant difference in aPKC activity on either side ( $p>0.05)$. (C) 28 days post-injury, aPKC activity is significantly higher in $\mathrm{C}_{2}$ hemisected rats $\mathrm{v}$. shams, regardless of side $(\mathrm{p}=0.011)$. In individual comparisions, aPKC activity is increased on the side contralateral to $\left(\mathrm{C}_{2} \mathrm{HS}\right.$ v. sham, $\left.\mathrm{p}=0.018\right)$, but not ipsilateral to injury $\left(\mathrm{C}_{2} \mathrm{HS}\right.$ v. sham, $\left.\mathrm{p}=0.096\right)$. (D) Atypical PKC activity is significantly increased 28 days versus one day post-injury $(\mathrm{p}=0.015)$. 
A

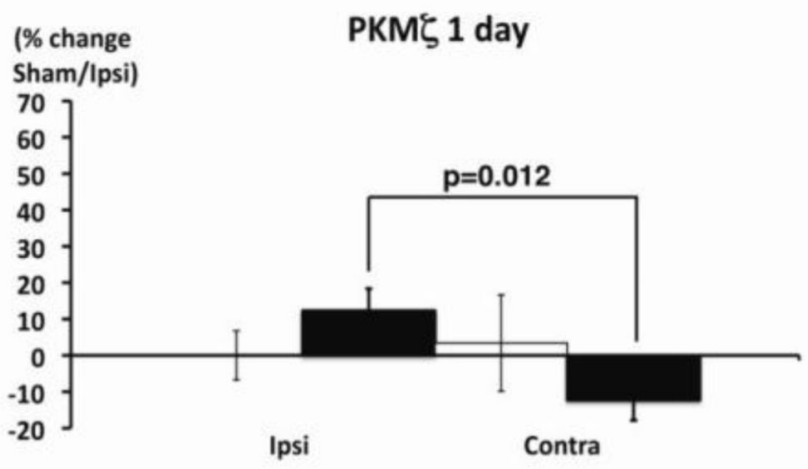

B

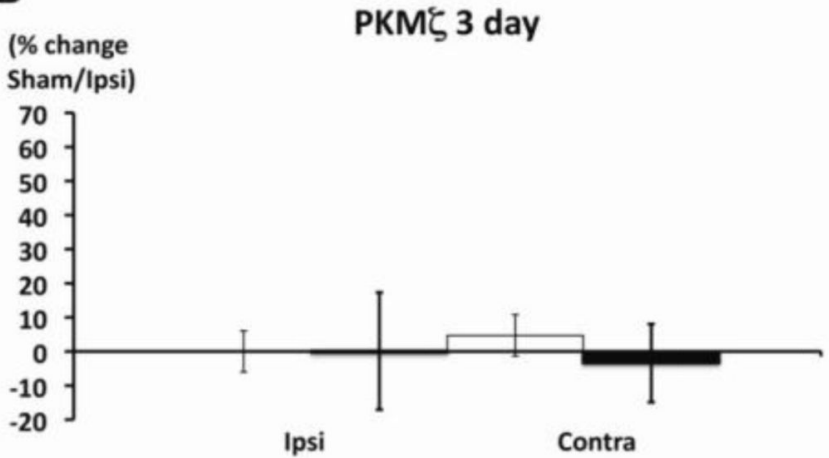

C

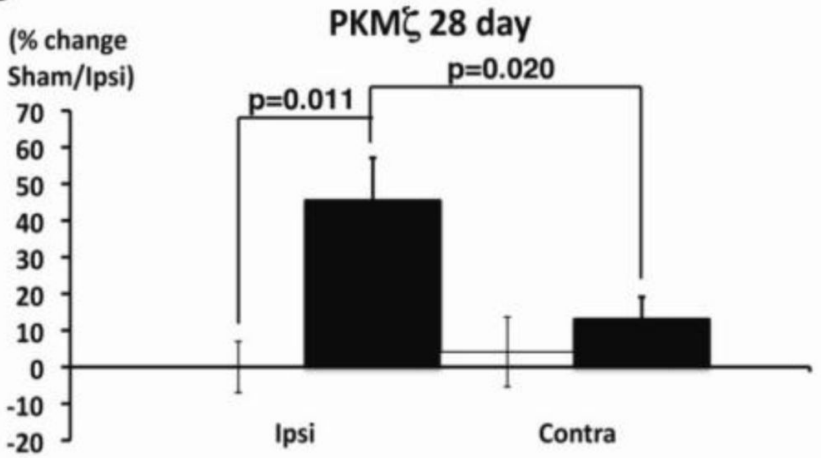

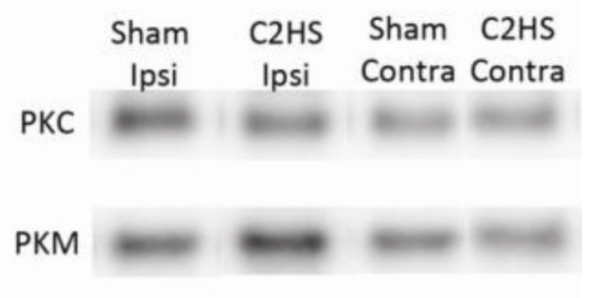
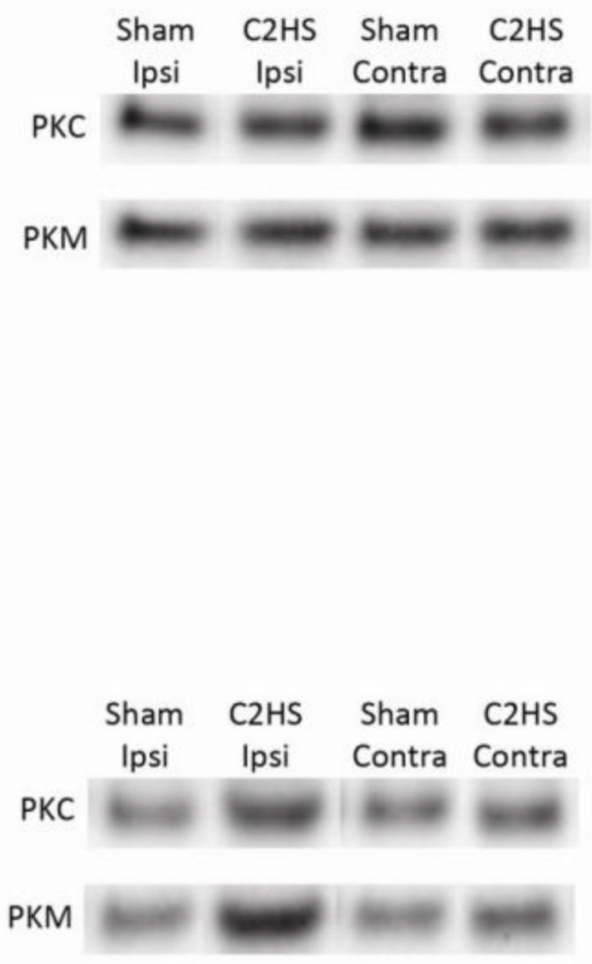

Figure 3.

Total PKM $\zeta$ protein levels are elevated 28 days post- $\mathrm{C}_{2}$ hemisection. $\mathrm{PKC} \zeta / \imath$ and $\mathrm{PKM} \zeta$ expression were measured by immunoblots in ventral $\mathrm{C}_{3-5}$ homogenates either ipsi- or contralateral to injury from sham (white bar) and $\mathrm{C}_{2}$ hemisected (black bar) rats. (A) One day post-injury, PKMS expression is significantly higher on the ipsilateral versus contralateral sides following a $\mathrm{C}_{2} \mathrm{HS}$ (ipsi v. contra, $\mathrm{p}=0.012$ ), but neither side is significantly different from sham rats. (B) Three days post-injury, there were no significant differences in PKM $\zeta$ expression on either side ( $\mathrm{p}>0.05$ ). (C) 28 days post-injury, PKM $\zeta$ expression is significantly higher ipsilateral to injury $\left(\mathrm{C}_{2} \mathrm{HS}\right.$ v. sham, $\mathrm{p}=0.011$; ipsi v. contra, 
$\mathrm{p}=0.020$ ). On right, typical gels exemplify change in PKM $\zeta$, but there were no consistent changes in other aPKC isoforms. 
A

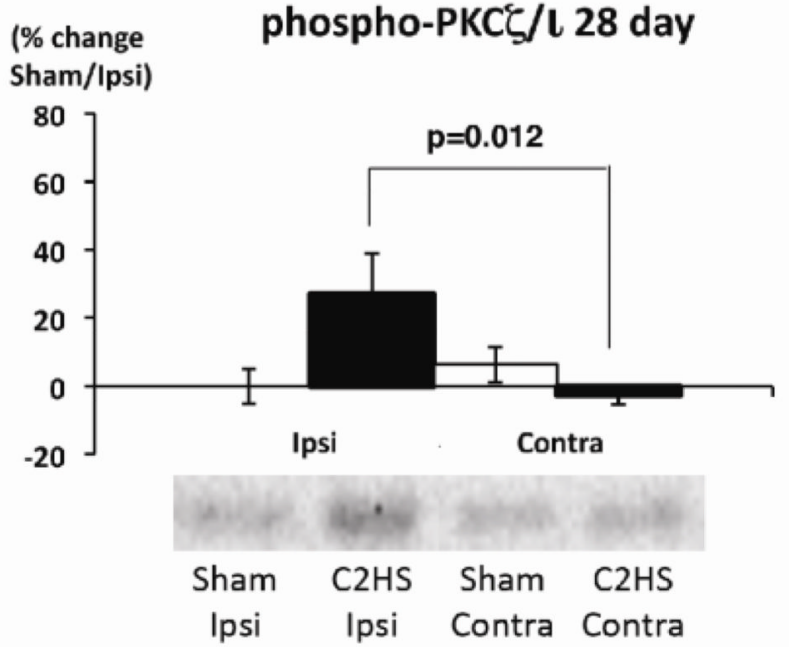

B

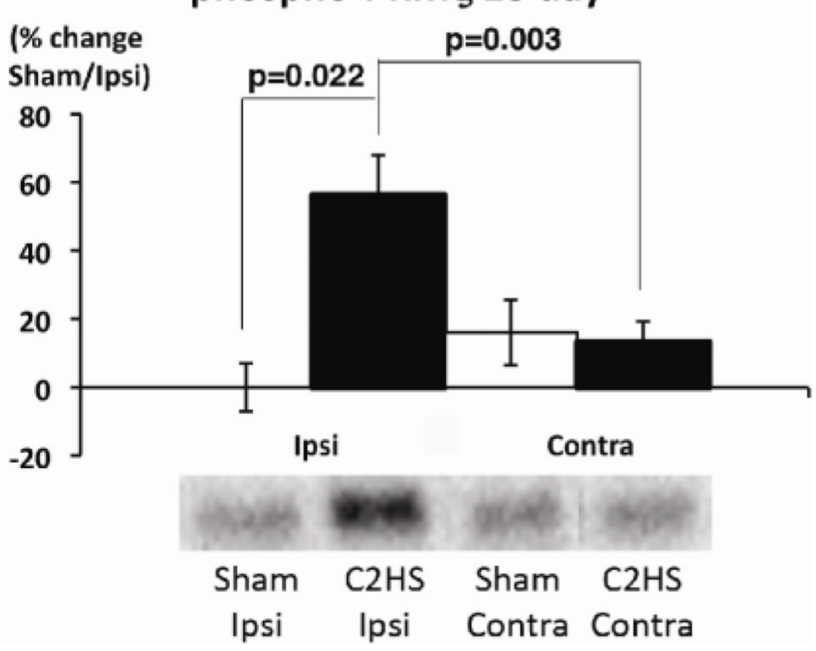

Figure 4.

Phosphorylated levels of $\mathrm{PKC} \zeta / \imath$ and $\mathrm{PKM} \zeta$ are elevated 28 days post- $\mathrm{C}_{2}$ hemisection. Phosphorylated aPKC expression was measured by immunoblots in ventral $\mathrm{C}_{3-5}$ homogenates either ipsi- or contralateral to injury from sham (white bar) and $\mathrm{C}_{2}$ hemisected (black bar) rats. (A) 28 days post-injury, phosphorylated $\mathrm{PKC} \zeta / \imath$ expression is significantly increased on the ipsilateral versus contralateral sides $(\mathrm{p}=0.012)$, although neither side was significantly different from sham rats. (B) 28 days post-injury, phosphorylated PKM $\zeta$ expression is significantly higher ipsilateral, but not contralateral to injury $\left(\mathrm{C}_{2} \mathrm{HS}\right.$ v. sham, $\mathrm{p}=0.022$; ipsi v. contra, $\mathrm{p}=0.003$ ). 

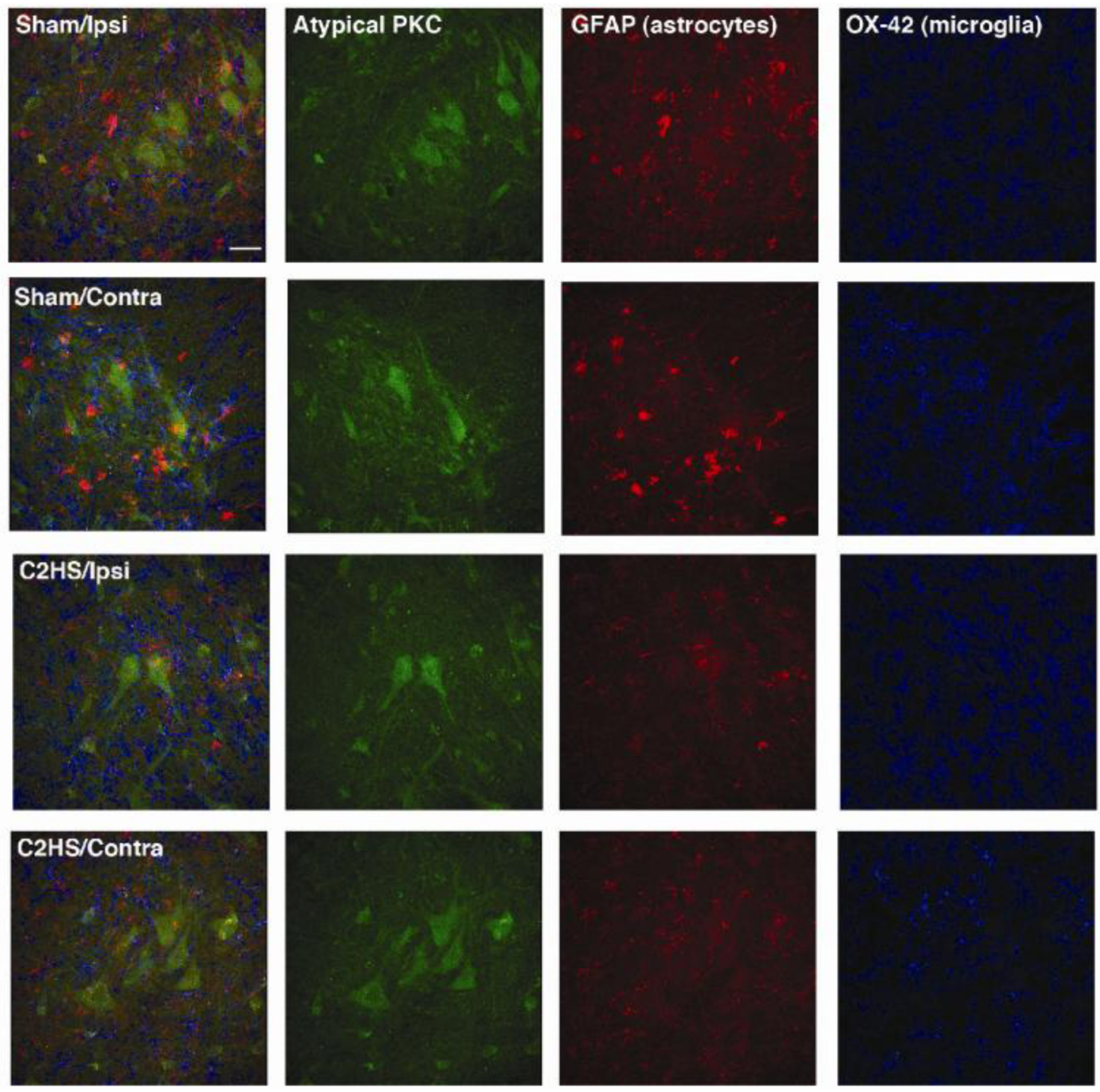

Figure 5.

Atypical PKC is expressed in presumptive phrenic motor neurons in sham operated and $\mathrm{C}_{2}$ hemisected rats. All images are from the ventrolateral region of the ventral horn at $\mathrm{C}_{4} 28$ days post-surgery. The left column of panels are the combined images of aPKC (green), GFAP (astrocytes, red) and OX-42 (microglia, blue). Scale bar $=40 \mu \mathrm{m}$. 
Table 1

Characteristics of antibodies

\begin{tabular}{|c|c|c|c|c|}
\hline & Species/type & Antigen & Dilution & Source \\
\hline $\operatorname{PKCS}(\mathrm{C}-20)$ & Rabbit polyclonal & C-terminus of PKCS & $1: 1000$ & SantaCruz \\
\hline phospho PKC $\zeta$ (pT560) & Rabbit monoclonal & Phospho Threonine 560 of PKCS & $1: 10,000$ & Epitomics \\
\hline $\mathrm{PKC \imath}$ & Mouse monoclonal & Human PKC々 aa. 404-87 & $1: 1000$ & BD Labs \\
\hline GAPDH & Mouse monoclonal & Glyceraldehyde-3-PDH (GAPDH) & $1: 10,000$ & Millipore \\
\hline GFAP & Chicken polyclonal & Purified bovine GFAP & $1: 1000$ & Millipore \\
\hline $0 \times 42$ & Mouse monoclonal & Cell peritoneal macrophages & $1: 100$ & SantaCruz \\
\hline
\end{tabular}

Exp Neurol. Author manuscript; available in PMC 2013 April 01. 


\section{Table 2}

Multivariate regression analysis comparing protein expression of atypical PKC isoforms with enzyme activity using data from both ipsi- and contralateral sides to injury following all days of recovery.

\begin{tabular}{|c|c|c|c|c|}
\hline Relative to activity & $\mathbf{R}$ & $\mathbf{R}^{2}$ & $\mathbf{F}$ & $\mathbf{P}$ \\
\hline $\mathrm{PKC} \zeta / \imath, \mathrm{P}-\mathrm{PKC} \zeta / \imath$ & 0.187 & 0.0349 & 0.885 & 0.419 \\
\hline 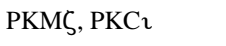 & 0.434 & 0.188 & 5.682 & $0.006^{*}$ \\
\hline $\mathrm{PKC \imath}$ & 0.32 & 0.102 & 5.684 & $0.021 *$ \\
\hline PKM $\zeta$ & 0.141 & 0.0199 & 1.013 & 0.319 \\
\hline
\end{tabular}




\section{Table 3}

Multivariate regression analysis comparing protein expression of atypical PKC isoforms with enzyme activity using data from ipsilateral side to injury following all days of recovery.

\begin{tabular}{|c|c|c|c|c|}
\hline Relative to activity & $\mathbf{R}$ & $\mathbf{R}^{2}$ & $\mathbf{F}$ & $\mathbf{p}$ \\
\hline 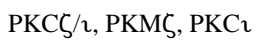 & 0.822 & 0.675 & 15.254 & $<0.001^{*}$ \\
\hline $\mathrm{PKC} \zeta / \imath, \mathrm{PKM} \zeta$ & 0.733 & 0.537 & 13.326 & $<0.001^{*}$ \\
\hline $\mathrm{PKC \imath}$ & 0.53 & 0.281 & 9.388 & $0.005^{*}$ \\
\hline
\end{tabular}




\section{Table 4}

Multivariate regression analysis comparing protein expression of atypical PKC isoforms with enzyme activity using data from contralateral side to injury following all days of recovery.

\begin{tabular}{|c|c|c|c|c|}
\hline Relative to activity & $\mathbf{R}$ & $\mathbf{R}^{2}$ & $\mathbf{F}$ & $\mathbf{p}$ \\
\hline $\mathrm{PKC} / / \imath, \mathrm{P}-\mathrm{PKC} \zeta / \imath, \mathrm{PKC} \imath$ & 0.497 & 0.247 & 2.404 & 0.095 \\
\hline $\mathrm{PKC} \zeta / \imath, \mathrm{PKC \imath}$ & 0.433 & 0.188 & 2.657 & 0.092 \\
\hline
\end{tabular}

